\title{
Cellulose biosynthesis in plants - the concerted action of CESA and non-CESA proteins
}

\author{
M. JURANIEC* and B. GAJDA \\ Department of Plant Ecophysiology, Faculty of Biology and Environmental Protection, University of Lodz, \\ PL-90237 Lodz, Poland
}

\begin{abstract}
Cellulose is the most abundant polysaccharide produced by plants. In the form of rigid microfibrils surrounding the cells, cellulose constitutes the load-bearing cell wall element that controls cell growth and shape. Cellulose microfibrils are laid down outside the cell by the multimeric plasma membrane-inserted cellulose synthase complexes (CSCs), which move along underlying cortical microtubules (CMTs). In plants, CSCs are shaped as rosettes with six lobes symmetrically arranged in a hexagonal structure. In Arabidopsis, the CSC is composed of at least three functionally non-redundant cellulose synthase (CESA) glycosyltransferases in both primary and secondary cell walls. The number, organization, and interactions of CESA proteins within the CSC have been debated for many years on the basis of numerous lines of evidence provided by electron microscopy, biochemical and genetic approaches, spectroscopic techniques, as well as computational modeling. The Arabidopsis thaliana model was extremely useful in elucidating the molecular composition of CSC and enabled to elucidate the specialized functions of distinct AtCESA isoforms. Several additional, non-CESA proteins involved in cellulose synthesis and its regulation were also identified in Arabidopsis. This review outlines the latest findings on CSC organization, trafficking, and plant-specific proteins directly associated with the complex and interconnecting CESAs with CMTs.
\end{abstract}

Additional key words: Arabidopsis thaliana, cellulose microfibrils, cellulose synthase complex, cortical microtubules, membrane proteins, mutants.

\section{Introduction}

Cellulose, a linear homopolymer of $(1 \rightarrow 4)$ - $\beta$-linked glucose (Glc) residues, is the most abundant polysaccharide on earth because it constitutes more than half of biomass produced annually (Vanholme et al. 2013). Most of the cellulose is produced by vascular plants but cellulose is also synthesized by algae, bacteria, or fungi (Nobles et al. 2001). In nature, cellulose very rarely occurs as separate glucan chains. From the moment of their synthesis by cellulose synthase complexes (CSCs) they associate by intermolecular hydrogen bonds into various higher-order structures in form of extracellular microfibrils of varying degrees of crystallinity and stiffness, and therefore, cellulose can play multiple functions. In Acetobacter xylinum, ribbons of cellulose form a raft supporting the bacteria floating at an air-water interface while in Agrobacterium tumefaciens cellulose is implicated in

Submitted 17 July 2019, last revision 25 October 2019, accepted January 22020.

Abbreviations: AP - adaptor protein, BiFC - bimolecular fluorescence complementation, BR - brassinosteroid, CC - companion of cellulose synthase, CESA - cellulose synthase, CME - clathrin-mediated endocytosis, CMF - cellulose microfibril, CMT - cortical microtubule, CMU - cellulose synthase-microtubule uncoupling, COB - COBRA, CSC - cellulose synthase complex, CSR - classspecific region, CTL1/POM1 - CHITINASE-LIKE1/POM-POM1, CW - cell wall, FF-TEM - freeze-fracture transmission electron microscopy, GFP - green fluorescent protein, Glc - glucose, GT - glycosyltransferase, HVR - hypervariable region, KOB1 - KOBITO1, KOR1 - KORRIGAN1, MT - microtubule, P-CR - plant conserved region, PCW - primary cell wall, PM - plasma membrane, POM2/ CSI1 - POM-POM2/CELLULOSE SYNTHASE-INTERACTIVE1, PTL1 - PATROL1, SAXS - small-angle x-ray scattering, SCW - secondary cell wall, SmaCC/MASC - small subcellular CESA compartment/MT-associated cellulose synthase compartment, STL STELLO, TEM - transmission electron microscopy, TGN - trans Golgi network, TMH - transmembrane helix, UDP - uridine diphosphate, WT - wild-type, Y2H - yeast two-hybrid.

Acknowledgments: The authors thank Dr. M. Gonneau (Institut Jean-Pierre Bourgin, INRA Versailles-Grignon, France) for her valuable comments and suggestions.

* Corresponding author; fax: (+48) 4263544 23, e-mail: michal.juraniec@biol.uni.lodz.pl 
pathogenesis by binding the bacteria to the host cell (Ross et al. 1991). In plant and algal cell walls (CWs), cellulose is the load-bearing component that forms a fibrilar mesh molding the shape of a cell, defining its physical and mechanical properties and controlling the direction of cell expansion (Kerstens and Verbelen 2003). Cellulose represents $10-30 \%$ of dry mass of primary cell wall (PCW) and $50-60 \%$ of secondary cell wall (SCW). In specialized cells as in cotton or flax fibers with thick SCWs, cellulose content reaches up to $98 \%$. The arrangement of glucan chains within cellulose microfibrils (CMFs) is not uniform. Current model explains that CMF is formed by a truecrystal core where chains are considered truly crystalline and by para-crystalline surface sheets with non-crystalline chains that associate with non-cellulosic polymers (Viëtor et al. 2002, Ding and Himmel 2006). In some cellulosedeficient mutants or in presence of cellulose biosynthesis inhibitors (e.g. Isoxaben, CGA 325'615), an accumulation of amorphous glucan was observed (Arioli et al. 1998, Peng et al. 2001). CMFs differ in their size depending upon the species, tissues, developmental stage as well as type of wall in which they are assembled. They are $5-10 \mathrm{~nm}$ large in PCWs and up to $\sim 50 \mathrm{~nm}$ in SCWs (Herth 1983, SatiatJeunemaitre 1992, Donaldson 2007, Fernandes et al. 2011, Zhang et al. 2014). In cotton fibers, CMFs are $\sim 10 \mathrm{~nm}$ wide and contain even $\sim 80$ glucan chains. Many authors reported, however, a diameter of $\sim 3.5 \mathrm{~nm}$ or even less for a single - elementary CMF in various plant species (e.g., Ha et al. 1998, Kennedy et al. 2007, Thomas et al. 2013).

Biosynthesis of cellulose is a complex process involving many actors and several steps: trafficking of multiple cellulose synthase (CESA) catalytic subunits to the plasma membrane (PM) and their subsequent attachment to the array of cortical microtubules (CMTs) that run along the PM cytoplasmic face, simultaneous polymerization of Glc molecules into long chains and their translocation across the PM, and parallel coalescence of multiple glucan chains into a microfibril. Apart from CESAs, other proteins necessary to cellulose synthesis and its regulation were identified counting these that directly link CSC to CMTs. The movement of the CSCs in the plane of the PM is driven by cellulose synthesis with nascent $\mathrm{CMFs}$ being deposited in linear trajectories along CMTs (Paredez et al. 2008). Uridine diphosphate-glucose (UDP-Glc) is a direct substrate for cellulose synthesis. Sucrose synthase, which produces UDP-Glc from sucrose, was shown to be associated with CSCs and involved in cellulose synthesis by channeling UDP-Glc to CESAs (Amor et al. 1995). Differences in CESA structure among kingdoms and taxa determine the structural variation in CSCs which adopt different shapes and sizes. Relationship exists between the geometry of the complex and the shape, size and degree of crystallinity of produced CMFs (Tsekos 1999, Roberts and Roberts 2007). Linear CSCs, arranged in single or multiple rows are found in bacteria, most algae and cellulose-synthesizing animals. For example, the alga Valonia has very large CSCs and synthesizes one of the largest, $\sim 20$-nm wide, highly crystalline CMFs. In contrast, charophycean algae, mosses, ferns and vascular plants have hexagonal rosette-shaped CSCs with $\sim 25-\mathrm{nm}$ diameter in the transmembrane region and larger in the cytoplasmic region (Mueller and Brown 1980, Delmer 1999, Nixon et al. 2016). This review summarizes the groundbreaking achievements and the most recent findings in the field of cellulose synthesis in plants with special attention to the functions of CESA and recently identified non-CESA proteins.

\section{Genes CESA and proteins CESA}

A tremendous progress has been achieved in the identification of proteins involved in cellulose synthesis, however, the biosynthetic process itself still remains tenuous. Genes responsible for cellulose synthesis were first identified in bacteria A. xylinum (Saxena et al. 1990, Wong et al. 1990). The product of AxCESA gene belongs to processive $\beta$-glycosyltransferases (GTs) and was shown to bind the UDP-activated Glc (Lin et al. 1990). Based on gene sequence similarity with AxCESA genes, Pear et al. (1996) identified two expressed sequence tags from cDNA clones obtained from RNA of cotton (Gossypium hirsutum) fibers at the stage of intense SCW synthesis. The two genes encoding putative CESAs were cloned and designated as GhCESA1 and GhCESA2. The ability to bind UDPGlc by CESA1 protein central fragment (containing four catalytic motifs) expressed in $E$. coli, led to the conclusion that the plant genes were true homologues of the bacterial CESAs (Pear et al. 1996). Plant CESA genes were larger than their bacterial counterparts and contained plantspecific insertions separating the conserved motifs from each other (Fig. 1A). Sequence alignments revealed the presence of conserved catalytic domain formed by three aspartic acid residues (D) and the QXXRW signature in bacterial and plant processive $\beta$-GTs (Saxena and Brown 1997). Independently, Arioli et al. (1998) using a mapbased cloning showed that cellulose-deficient phenotype in dwarf radial swellingl ( $r s w 1)$ Arabidopsis mutant resulted from an amino acid change $(\mathrm{A} \rightarrow \mathrm{V})$ in AtCESA1. Since then, CESA genes have been identified in many other species. Finally, Kimura et al. (1999) demonstrated by immunocytochemical labeling with specific antiCESA antibodies that rosette CSC co-localized with CESA catalytic subunit at the cytoplasmic face of freezefractured membranes in Vigna angularis proving that the PM-bound complex is the site of cellulose synthesis in vascular plants. However, first attempts to isolate active CESAs from plants (or by recombinant expression) failed. Conventional biochemical methods including detergent solubilization of intact complexes from microsomal/ membrane fractions have been unsuccessful because of the high CSC instability. Only limited amounts of $(1 \rightarrow 4)-\beta$-glucan and little or no CESA activity was detectable above a high background of callose synthase activity in vitro (Kudlicka and Brown 1997, Lai-Kee-Him et al. 2002, Cifuentes et al. 2010).

Plant CESAs share a number of conserved structural features including eight transmembrane helices (TMHs), two at the N-terminus and six at the $\mathrm{C}$-terminus that border a cytoplasmic domain, as well as an N-terminus with 

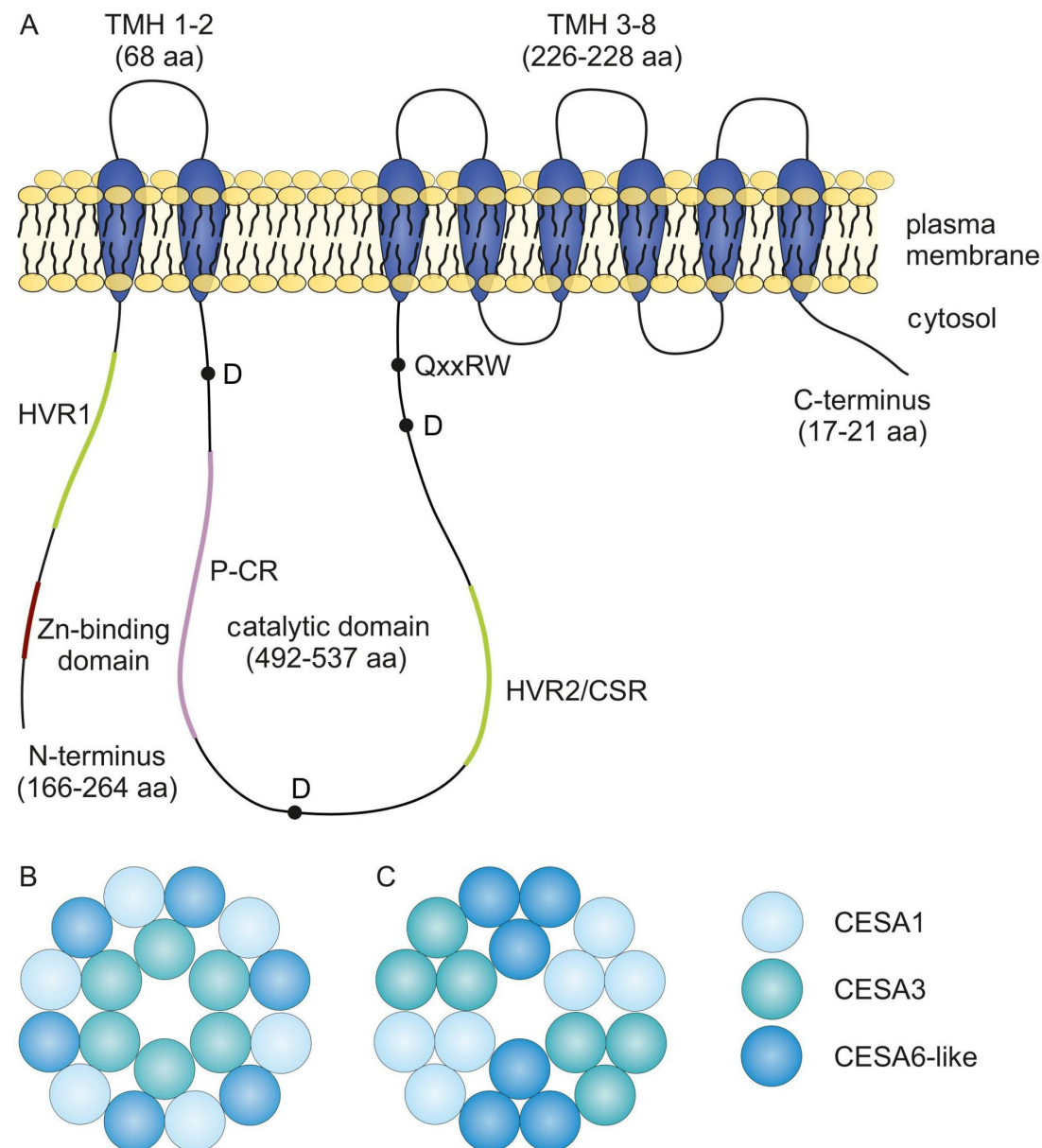

CESA1

CESA3

CESA6-like

Fig. 1. A scheme of Arabidopsis thaliana cellulose synthase (CESA) structure $(A)$ and the current 18-CESA model showing the putative arrangements of three distinct CESA isoforms within the complex $(B$ and $C)$. $A$ - A schematic representation of the CESA polypeptide with domain length. Transmembrane helices (TMH 1-8) are marked in blue. At the N-terminal is a cysteine-rich zinc-binding domain and a hyper-variable region (HVR1) rich in acidic amino acids (aa). The central catalytic domain contains aspartic acid residues (D), which bind the UDP-glucose substrate and the conserved D, QxxRW motif characteristic for processive glycosyltransferases. The plant conserved region (P-CR) and the second hyper-variable region (HVR2), also referred to as a class specific region (CSR), located also within the cytosolic domain, are both important for plant-specific aspects of CESA function as interactions with other proteins involved in cellulose synthesis or oligomerization to form the rosette shape. $B$ - The 'hexamer of heterotrimers' model proposed by Newman et al. (2013) and by Hill et al. (2014) in a 1:1:1 CESA ratio with consistent protein-protein interactions. The complex is composed of six lobes consisting each of three different CESAs (modified from Hill et al. 2014). C - The 'hexamer of homotrimers' model formulated by Vandavasi et al. (2016), which also fulfills the rules for the constituent number of CESA proteins within the complex described by Hill et al. (2014) (modified from Vandavasi et al. 2016).

Cys-rich Zn-binding domain which is probably involved in the dimerization of CESAs through the formation of disulfide bridges (Kurek et al. 2002) (Fig. 1A). Moreover, the cytosolic N-terminus contains a HVR1 region of $\sim 150$ aa that is hyper-variable between CESA paralogs but conserved between orthologs (Nakagami et al. 2010, Facette et al. 2013). A cytosolic 540-aa domain, forming the active site for UDP-Glc substrate binding to the glucan terminus, is located between TMHs 2 and 3 (Fig. 1A). TMHs form a channel through which the newly synthesized glucan chain translocates outside the cell. The studies of the CESA crystal structure from Rhodobacter sphaeroides enabled to establish a model of glucan chain elongation (Morgan et al. 2013, Slabaugh et al. 2014). The authors suggested that glucan chain translocates one Glc at a time and that each newly attached Glc molecule rotates in the opposite direction around the acetal linkage to align within the same plane of the $(1 \rightarrow 4)-\beta$-glucan forming the $180^{\circ}$ angle between neighbouring molecules (Morgan et al. 2013). GTs share a common mechanism of catalysis and, as reported by Sethaphong et al. (2013), a high degree of structural convergence exists between the catalytic sites of eukaryotic and prokaryotic CESAs indicating a conserved mechanism of cellulose production in plants including a single active site per CESA polypeptide chain. In AtCESAs, the cytosolic domain contains a 126-aa plant-conserved region (P-CR) between $D_{1}$ and $\mathrm{D}_{2}$ and another hypervariable region (HVR2) or CSR (class-specific region) of $86-106$ aa between $\mathrm{D}_{2}$ and $\mathrm{D}_{3}$ (Pear et al. 1996, Vergara and Carpita 2001, Carroll and 
Specht 2011) (Fig. 1A). Both regions are only present in rosette type of CSCs suggesting the role in CESA-CESA interactions and rosette assembly, for instance CESAs in algae with linear complexes do not have CSRs (Roberts and Roberts 2009, Sethaphong et al. 2016). Although a 3D atomistic model of entire plant CESA polypeptide remains unavailable, a tertiary model of cytosolic domain of GhCESA showed that these plant-specific sequences fold into distinct subdomains on the perimeter of the catalytic region indicating their role in self-oligomerization of CESAs (Sethaphong et al. 2013). They may also provide additional regulation sites such as phosphorylation site (Chen et al. 2010). Clustering of CESAs was based on sequence divergence within CSRs. Interestingly, the gene sequence similarity is greater among orthologs from different species than among paralogs of the same species (Vergara and Carpita 2001, Carroll and Specht 2011).

The availability of sequenced genomes allowed cataloguing of CESA genes into families (Richmond and Somerville 2000, Carroll and Specht 2011). The Arabidopsis CESA family members subdivide into 6 clusters with orthologous genes from other species reflecting functional specialization of distinct CESA isoforms. Their specific roles were explained on the basis of expression patterns and phenotypical analysis of corresponding CESA mutants. Two functional groups among AtCESAs have been distinguished: AtCESA1, AtCESA3 and AtCESA6-like necessary for PCW cellulose synthesis and AtCESA4, AtCESA7 and AtCESA8 required during SCW development (Taylor et al. 2003, Desprez et al. 2007, Persson et al. 2007). Four remaining isoforms are implicated in tissue-specific processes (Gardiner et al. 2003, Desprez et al. 2007, Persson et al. 2007). AtCESA4, -7 and -8 have no paralogs and possess at least one ortholog in other species. In rice, OsCESA4, OsCESA7 and OsCESA9 were shown to be implicated in SCW cellulose biosynthesis (Tanaka et al. 2003). Two functionally distinct sets of genes were also found in poplar (Djerbi et al. 2005), eucalyptus (Ranik and Myburg 2006), barley (Burton et al. 2004), or maize (Appenzeller et al. 2004). Cellulose synthases are evolutionary conserved and functional differentiation was anterior to the monocotyledons/dicotyledons divergence and, at least for CESA4, -7 and -8, the Angiosperms/ Gymnosperms divergence (Nairn and Haselkorn 2005, Little et al. 2018). Moreover, the analysis of the CESA sequences in the moss Physcomitrella patens revealed that there were no orthologs for different plant CESAs in the moss genome indicating that the specialization of CESA isoforms evolved after the divergence of plant and moss CESAs (Roberts and Bushoven 2007). Since the functional specialization of CESAs is a more recent event than the appearance of functional hexameric rosettes, it may suggest their regulatory functions rather than geometrical and/or biochemical constraints within the rosette-CSC.

The AtCESAs genes are expressed in different tissues and to varying profiles throughout the life of a plant. Distinct AtCESAs of similar function are co-expressed in the same cell type. While AtCESA 1, -3 and -6 transcripts are present in most tissues, AtCESA4, -7 and -8 are specifically expressed during the SCW synthesis in developing xylem and interfascicular fibres. CESA1, -3 and -6 are necessary for the cellulose synthesis in developing seedling organs, such as root and hypocotyl. The corresponding mutants (cesal $1^{r s w l}, c^{2 e s a 3^{e l i l}}$ and cesa6 ${ }^{\text {prcl }}$ ) have comparable phenotypes: dwarfism with increased radial cell expansion, cellulose deficiency and/or severe inhibition of the synthesis of crystalline microfibrils (Arioli et al. 1998, Fagard et al. 2000, Caño-Delgado et al. 2003). Mutations in AtCESA1 and -3 result in a much stronger phenotype than mutation in AtCESA6. AtCESA3 is unique but AtCESA1 has one paralog - AtCESA10 whereas AtCESA6 has three paralogs: AtCESA2, -5, -9. Transcriptome data demonstrate that AtCESA9 is specifically expressed in stamens and embryos whereas AtCESA10 in siliques thus both are not involved in the redundancy mechanism during seedling development. Interestingly, AtCESA5 is specifically expressed in epidermal cells of the seed coat where it is necessary for cellulose synthesis in adherent mucilage (Sullivan et al. 2011). Since the cesal and cesa3 knockout alleles are lethal, the involvement of CESA1 and CESA3 in mucilage cellulose synthesis is difficult to study using a reverse-genetic approach. The strong cesa5 mutant phenotype indicates that other isoforms do not compensate its deficiency. This stands in opposition to vegetative tissues where the isoforms redundant with CESA6 can rescue, at least partially, the growth phenotype (Fagard et al. 2000, Desprez et al. 2007). CESA 2 and CESA 5 partially overlap CESA6 in function but the phenotype of cesa2cesa6 double mutant and lethality of cesa5cesa 6 indicated that the presence of CESA5 or CESA6 is mandatory for the CSC assembly (Desprez et al. 2007). The irregular xylem (irx) mutations in AtCESA4, -7 and -8 (cesa4 ${ }^{\text {irx }}$, cesa $7^{\text {irx }}$ and cesa8 ${ }^{\text {irxl }}$, respectively) cause a collapse of mature xylem cells due to the lack of SCW thickenings (Turner and Somerville 1997, Taylor et al. 2003). The irx inflorescence stems are characterized by a several-fold decrease in the amount of cellulose in respect to wild type (WT) and all three loci appear equally important in SCW cellulose synthesis. In these mutants, the absence of one CESA protein was neither compensated by the remaining two nor by the over-expression of other CESAs, which indicates that these three isoforms are not redundant. Co-purification and coimmunoprecipitation with specific antisera confirmed that CESA1, -3 and -6 as well as CESA4, -7 and -8 are parts of the same protein complex, respectively (Taylor et al. 2003, Desprez et al. 2007). The combination of three nonredundant isoforms may be necessary to form a functional CSC for several reasons: 1) they may provide distinct sites for specific intra- and intermolecular interactions for the assembly of the complex, 2) they may provide specific regulatory functions, or 3) they may catalyze initiation and polymerization reactions of distinct glucan chains. Although the experimental evidence suggests the combination of three different isoforms, a crossfunctionality between some PCW and SCW isoforms occurs as CESA1 partially complemented the defects of cesa8 while CESA7 partially rescued the phenotype of a weak allele of cesa3 (Carroll et al. 2012). Birnbaum et al. 
(2003) showed that PCW and SCW CESAs can be coexpressed in specific cell types which suggests that mixed PCW/SCW CSCs may exist for cellulose synthesis during the transition between the PCWs and SCWs. Moreover, yeast two-hybrid $(\mathrm{Y} 2 \mathrm{H})$ and bimolecular fluorescence complementation (BiFC) assays revealed a promiscuity in one-to-one CESA isoform physical interactions including formation of homodimers and heterodimers in most of possible combinations between both PCW and SCW CESAs (Desprez et al. 2007, Timmers et al. 2009, Carroll et al. 2012, Li et al. 2013). The specificity in CESA interactions within functional CSCs is determined most probably by the simultaneous interactions of three isoforms and high promiscuity observed in pair-wise assays do not reflect CESA interactions in planta. The short C-terminus is conserved in CESA3, -4, -6 and -7 but not in CESA1 and -8 (Carroll and Specht 2011) which suggests an additional isoform selectivity through CSC assembly (or competition between partners) and that CESAs may play different roles. Using chimeric AtCESA1 and AtCESA3 proteins (both functionally non-redundant), Wang et al. (2006) demonstrated in corresponding mutant backgrounds that the identity of the catalytic and/or C-terminal domains determine the conserved function and thus the position within the CSC. The experiments with chimeric CESA4, -7 and -8 with swapped protein domains showed that all three: the central domain and both $\mathrm{N}$ - and C-terminal regions differently contributed to class-specific functions (Hill et al. 2018). On the contrary, Sethaphong et al. (2016) showed that the variable CSRs of CESA1 and CESA3, having both the most similar aa sequence among AtCESAs, are interchangeable in vivo and do not determine their non-redundant functions. The AtCESA1CESA3CSR and AtCESA3-CESA1CSR chimeric proteins restored growth in cesal ${ }^{r s w 1}$ and cesa $3^{\text {jes }}$ backgrounds, respectively, showing that the sole CSR is not sufficient to confer the isoform specificity within native CSCs.

\section{Transcriptional and post-translational regulation of CESAs}

Cellulose biosynthesis is highly regulated at multiple levels and synchronized with growth and differentiation. CESA genes vary in their transcript profiles, with isoforms specifically expressed during embryogenesis, cell elongation, or formation of the SCW. The co-expressions of PCW or SCW CESAs are in line with the observations that CSCs are formed by at least three different CESA isoforms (Brown et al. 2005, Persson et al. 2005). Interestingly, although AtCESA7 transcription in stems was two to three times higher than that of AtCESA8 (Brown et al. 2005), SCW CSCs showed equal CESA stoichiometry (Hill et al. 2014). A global Affymetrix Arabidopsis microarray analysis provides evidence that some genes involved in several pathways are co-regulated with two functionally distinct AtCESA types (Persson et al. 2005). For instance, genes involved in brassinosteroid (BR) synthesis showed a co-regulation with CESA1, -3 , and -6 and not with CESA4, -7, and -8. The BRs control cell expansion and morphogenesis, processes associated with PCW rearrangements. Indeed, these phytohormones control the expression of CESA genes and regulate cellulose biosynthesis (Xie et al. 2011). The authors showed that an impairment in BR biosynthesis or perception induced a cellulose synthesis deficiency and that exogenously applied BR reverted the CESA expression deficiency in deetiolated2-1 mutant affected in BR synthesis. In contrast, it was not the case in BR-insensitive bri1-301, affected in $\mathrm{BR}$ receptor, indicating that $\mathrm{BR}$ signaling is crucial for CESA expression regulation. Moreover, the BR-activated transcription factor BES1 binds to CESA promoter regions in vivo (Xie et al. 2011). On the other hand, two functionally redundant NAC domain transcription factors, SND1 and NST1, are key regulators of the transcriptional cascade that is necessary for the SCW synthesis initiation in fibers of Arabidopsis stems (Zhong et al. 2010). Overexpression of MYB46 and MYB83 transcription factors, which are both NAC regulators' direct targets, upregulated SCW CESAs expression (Ko et al. 2009, McCarthy et al. 2009). Kim et al. (2013) showed that MYB46 binds to SCW CESA promoters. Many SCW-related gene promoters in Arabidopsis have MYB binding motifs called SMRE (SCW MYB-responsive element) or the MYB46responsive cis-regulatory elements (M46RE) which were shown to be crucial for SCW cellulose synthesis (Kim et al. 2012, Zhong and Ye 2012).

Other regulatory mechanisms including posttranslational modifications, the control of CSC abundance and the lifetime of PM-inserted CSCs are also possible. The dimerization of CESA proteins through the redoxregulated formation of disulfide bridges of the N-terminal Zn-binding domains may be crucial for rosette assembly (Kurek et al. 2002). Under oxidative conditions, GhCESA1 forms a dimer which is more resistant to ubiquitin-mediated degradation than the monomeric form indicating the role of N-terminal in complex stabilization. Phosphorylation can also regulate CESA activity, interactions or signaling cascades in response to environmental and/or developmental stimuli (Speicher et al. 2018). Global phosphoproteomic studies of the cytoplasmic regions of integral PM proteins from Arabidopsis and maize identified several Ser/Thr phosphorylation sites on CESA1, CESA3, and CESA5, mostly in HVR1 (Nühse et al. 2003, Nakagami et al. 2010, Facette et al. 2013). They are unique among CESA paralogs but conserved among orthologs in dicots and monocots. Moreover, short aa sequences surrounding phosphorylation sites, and known as kinase recognition sites, are conserved but not between the phosphorylation sites themselves indicating that regulation of distinct CESAs by different kinases is a conserved aspect of cellulose biosynthesis (Carroll and Specht 2011). The analyses with phosphonull and phosphomimic residues in various mutants revealed functional implications in vivo. Studies in the rswl-1 background showed that phosphorylation of CESA1 is required for normal cellulose content, CSC velocity and interactions with MTs (Chen et al. 2010). Similarly, Bischoff et al. (2011) observed in their experiments with cesa5 mutants a role for phosphorylation in the control of 
CSC velocity in relation with the activation of $\mathrm{red} / \mathrm{far}$ red photoreceptor (phytochrome B). The degree of CESA5 phosphorylation regulates the interactions with CMTs and thus the movement of CSC which enables the fine tuning of cellulose deposition in darkness. AtCESA4 and AtCESA7 are also phosphorylated within their HVRs and it was found that at least CESA7 is regulated via proteasomedependent pathway which could play a role in the stability of SCW CSCs (Taylor 2007).

\section{Organization of the rosette CSC}

Because the synthesis of cellulose results in highly organized crystallites, CESA catalytic subunits are believed to be also precisely organized within the complex. How many CESA proteins are necessary to form a functional CSC and how they interact has been discussed by numerous authors for decades. Given that one CESA GT polymerizes one cellulose chain, one CSC has approximately as many CESA subunits as many glucan chains are present in an elementary CMF. The long-held 36-CESA CSC model appeared in 80's mainly on the basis of the CSC size measurements and perpetuated through many years (Herth 1983, Delmer 1999, Doblin et al. 2002, Taylor et al. 2003, Ding and Himmel 2006) further supported by the pulldown and blue native (BN)/SDS-PAGE experiments on detergent-soluble extracts from Arabidopsis seedlings and stems (Wang et al. 2008, Atanassov et al. 2009). The authors detected different CESA oligomers including putative dimers, tetramers, and hexamers for both PCW and SCW CESAs. The largest complexes (of 740 to $840 \mathrm{kDa}$ ) were considered as hexamers. Nevertheless, the 36-CESA model has been often questioned on several grounds including overestimations in the CSC size using traditional freeze-fracture transmission electron microscopy (FF-TEM) as well as the calculations of a variable number of glucan chains forming elementary CMFs in different species. On the other hand, the 36CESA CSC model was further combined with the results of genetic studies giving rise to several models explaining the putative organization and interactions between nonidentical CESA proteins (Scheible et al. 2001, Doblin et al. 2002, Desprez et al. 2007, Persson et al. 2007, Timmers et al. 2009). Although, the genetic studies showed that functional CSCs are only formed when isoforms from each CESA class are combined (Taylor et al. 2003, Desprez et al. 2007, Carroll et al. 2012) they could not explain how various CESA proteins are arranged within the six lobes of the CSC, what their exact number is and how cells control their right positioning. An important step towards understanding the CESA composition within the CSC was achieved by Gonneau et al. (2014) and Hill et al. (2014) who showed the equimolar stoichiometry of CESA1, CESA3 and CESA6 in PCW CSCs and CESA4, CESA7 and CESA8 in SCW CSCs, respectively, by using co-immunoprecipitation combined with mass spectrometry and by quantitative immunoblotting with isoform-specific antibodies. However, these results did not answer the persisting questions either of the number of
CESAs building the complex $(6 \times 3=18$ or $6 \times 6=36)$ or their organization.

The number of glucan chains forming an elementary CMF reflects the number of catalytically active CESAs within the complex. The hexagonal structure of rosette CSC indicates that the number of chains in an elementary CMF must be a multiple of six. It was widely assumed that typical elementary CMFs in higher plants were composed of 36 glucan chains (Herth 1983, Delmer 1999). However, several measurements in various plant species (e.g. early electron diffraction data from cotton and rose communicated by Chanzy et al. 1978, 1979) indicated that PCW microfibrils contained as few as $12-25$ glucan chains. The number of glucan chains in an elementary CMF has not been determined in Arabidopsis. However, recent studies based on wide-angle X-ray scattering, small-angle neutron scattering, solid-state NMR, and computational simulations of different types of CWs including mung bean PCW, celery collenchyma and spruce wood converged on a $\sim 3-n m$ diameter which would correspond to $\sim 20$ chains (Fernandes et al. 2011, Newman et al. 2013, Thomas et al. 2013, Oehme et al. 2015). CMFs are not circular and the number of constituent chains ( $\sim 18$ to 24$)$ is determined by the cross-sectional shape. Given the 1:1:1 CESA ratio, the latest measurements of the size of CMFs and based on the rule that the number of glucan chains in a CMF must be divisible by six (the number of rosette lobes) and by three (non-identical CESA isoforms), Newman et al. (2013) and Hill et al. (2014) proposed the 'hexamer of heterotrimers' CSC model with 18 catalytically active CESAs. The 'hexamer of trimers' model was also formulated by Vandavasi et al. (2016) who observed the self-oligomerization of solubilized AtCESA1 monomers into stable trimers. The authors expressed the catalytic domain of AtCESA1 in E. coli and studied the structure of purified (in a folded conformation) monomers and trimers using small-angle X-ray scattering technique (SAXS). The comparison of the AtCESA1 trimer structure and size with the $\sim 15 \mathrm{~nm}$ diameter of a CSC lobe at the cytosolic side from TEM images strongly supported three CESA proteins per lobe instead of six that would occupy too much area. Interestingly, the oligomers of higher order were not detected, indicating that CESA cytosolic domains are responsible for lobe formation but do not contribute to CSC assembly. Both configurations, six heterotrimers or two sets of three distinct homotrimers are possible and fulfill the rules described by Hill et al. (2014) (Fig. 1B,C). Further comparison of AtCESA1 trimer computational models with SAXS profiles enabled to explain the putative orientation of monomers in the trimeric lobes where CSRs are found at the periphery of the cytosolic domain, within the vertices of the triangular lobe, and do not participate in any of the interfaces within the trimer, while P-CRs form the base of a trimer and are believed to interact with other proteins involved in cellulose synthesis (Vandavasi et al. 2016). Such an arrangement of CESA isoforms limits the complex to six lobes. Similar conclusions were drawn by Nixon et al. (2016) who validated previous observations by superimposing the average size and shape of CSCs obtained from FF-TEM images from $P$. patens with 
computational models for GhCESA1 TMH region as well as for the above mentioned AtCESA1 catalytic domain model based on SAXS profiling. The authors showed that trimeric lobes of the developed models correlated with individual lobe geometry and rosette morphology. In addition, they calculated that the assembly of trimers into a ring resulted in the lowest potential energy per monomer. Rosette diameters of TMH region obtained from FF-TEM pictures are variable with the mean value of $23.4 \mathrm{~nm}$ indicating weak interactions between lobes. This in turn suggests that forces stabilizing CSC must occur below and/ or above the TMH region. Although the trimeric CESA models lacked the $\mathrm{N}$-terminal region and the companion proteins, the estimated CSC diameter on the cytosolic side had in average $30 \mathrm{~nm}$ instead of previously proposed 45 - $50 \mathrm{~nm}$ (Bowling and Brown 2008). Assuming that $1 \mathrm{TMH}$ region occupies an area of $1.4 \mathrm{~nm}^{2}$ (Eskandari et al. 1998) and that one CESA protein possesses $8 \mathrm{TMHs}$, Bowling and Brown (2008) calculated that one CSC lobe would contain no more than 4 CESA proteins giving an area of $50.4 \mathrm{~nm}^{2}$ perfectly matching the area of $8-\mathrm{nm}$ circle $\left(50.3 \mathrm{~nm}^{2}\right)$ which corresponds to a single CSC lobe. Although spectroscopic and diffraction techniques support the 24-chain microfibrils, the 24-mer CSC is rather doubtful because the CESA number must be a multiple of six and divisible by three. Vandavasi et al. (2016) estimated a 15$\mathrm{nm}$ diameter for a lobe at the cytosolic side and a similar value for the size of the AtCESA1 catalytic domain trimer model demonstrating that maximum three CESAs form individual CSC lobes. Similarly, as shown by Nixon et al. (2016), the space below an average FF-TEM image of the CSC could be filled by trimeric SAXS models. In contrast to large algal CMFs, production of small 18-chain CMFs by land plants may have an adaptive implication giving more possibilities for their aggregation and the size of final CMFs and CW structure.

\section{Regulated trafficking CESA proteins}

The aptness to deliver CESAs to distinct sites at the cell surface and controlling their abundance is essential for cells to produce CMFs that control growth in a particular direction and/or under particular conditions. Indeed, the abundance and lifetime of CSCs impact the amount and properties of CMFs. CSCs were previously observed using TEM in the PM, at the periphery of the trans face of the Golgi apparatus and Golgi-derived vesicles (Haigler and Brown 1986). Live-cell imaging using fluorescently tagged CESAs allowed to follow the intracellular dynamics and the delivery of CESAs to the sites of cellulose production (Chan et al. 2007, Desprez et al. 2007, Crowell et al. 2009, Gutierrez et al. 2009). Green fluorescent protein (GFP)-CESA3 signals were observed in medial and trans-Golgi cisternae and co-localized with the transGolgi network (TGN) marker VHA-a1 (Crowell et al. 2009). TGN compartment plays a dual role, as a secretory sorting station it directs newly synthesized proteins to their subcellular destinations and as an early endosome it receives endocytosed recycled molecules. However, it is not clear whether CSCs present in TGN are destined for secretion or internalized from the PM. The presence of MTassociated vesicles containing temporarily stored GFPCESA3 was simultaneously discovered by two research groups and called respectively MT-associated cellulose synthase compartment (MASC) or small subcellular CESA compartment (SmaCC) (Crowell et al. 2009, Gutierrez et al. 2009). SmaCCs/MASCs are distinct from TGN and are not initially bound to MTs but associated with them after osmotic stress (or cellulose synthesis inhibitor treatment) and co-localized with TGN marker. SmaCCs/MASCs are thought to play a double role, as delivery vesicles, formed before the insertion of newly synthesized CSCs into the $\mathrm{PM}$, and as storage/recycling vesicles of CSCs internalized upon stress (Fig. 2). However, experiments using drug treatment suggest the latter function (Crowell et al. 2009, Gutierrez et al. 2009, Wightman and Turner 2010). Vesicles containing CSC are removed from the PM via clathrin-mediated endocytosis (CME), another regulatory mechanism controlling the abundance and distribution of CESAs in the PM (Bashline et al. 2013). In accordance, the growth phenotype and cellulose content are affected in single and multiple CME-deficient ap $2 m-1$ and twd40-23 Arabidopsis mutants (Bashline et al. 2015). An AP2M, the medium subunit of the CME adaptor protein 2 (AP2) complex responsible for internalization of cargo proteins to the PM, was shown to interact with mCherry-CESA6 mediating its endocytosis (Bashline et al. 2013). TWD40-2, a plant-specific protein, plays a similar role and cooperates with AP2M. Interestingly, in addition to its PM localization discussed in the last section, POM-POM2/CELLULOSE SYNTHASE-INTERACTIVE1 (POM2/CSI1), a CESAinteracting protein, is also associated with SmaCC/MASC compartments upon treatment with isoxaben and oryzalin (Bringmann et al. 2012, Lei et al. 2012) which suggests that POM2/CSI1 may play a role in CESA trafficking. Moreover, Lei et al. (2015) demonstrated that the protein is involved in SmaCC/MASC-mediated fast recovery of CSCs to the PM upon abiotic stress relief.

STELLO1 and 2, two other Golgi-localized proteins regulating the trafficking of CSCs were discovered in Arabidopsis (Zhang et al. 2016). In contrast to stll and stl2, stl1stl2 double mutant has much shorter primary root and dark-grown hypocotyl and produces less cellulose which indicates that both proteins are functionally redundant. The authors showed that the proteins interact with CESAs and that their GT activity is necessary for the proper assembly of CSCs. Changes in spatial distribution of CSCs in the Golgi and lower rate of their delivery to PM were observed in STL-deficient plants. Resulting CMFs are characterized by altered degree of crystallinity (Zhang et al. 2016). Apart from STLs, other actors were also shown to be cooperatively implicated in de novo secretion of CSCs in Arabidopsis including plant-specific PATROL1 (PTL1), POM2/CSI1 and octameric exocyst complex involved in vesicle trafficking (Lei et al. 2015, Zhu et al. 2018). While PTL1 and exocyst complex subunits are required for the delivery of CSCs to the PM, POM2/CSI1 functions as CMT marker defining the position of docking site.

Another example of regulated trafficking was provided 
by Miart et al. (2014) who showed that during cytokinesis CSCs are delivered to a newly laid down crosswall following a precise spatio-temporal pattern. The authors showed that the accumulation of CESA1, CESA3, and CESA6 as well as cellulose deposition occurred already at the tubulo-vesicular membrane network formation stage. CSCs are delivered to the cell plate by phragmoplastassociated vesicles, to MT-free zones of the expanding cell plate by mobile compartments (probably Golgi bodies) and finally CSCs are redirected via CME from the central part of a cell plate and from the mother cell PM to the peripheral zones of a growing cell plate which is accompanied by the GFP-CESA signal attenuation at the central region of the cell plate. The in vivo dynamics was also studied during SCW bands formation in protoxylem cells demonstrating that CSCs are recruited at high concentration at narrow membrane domains underlying SCW thickenings and that the velocity of CESA7-containing CSCs is faster than that of PCW CSCs (Watanabe et al. 2015). Both Golgiassociated and independent SmaCCs/MASCs are involved in a dynamic exchange of CSCs to the SCW domains. The changes observed in SCW CSCs velocity during cell differentiation suggest a temporal, next to gene expression, regulation of cellulose biosynthesis. For more in-depth discussion of cellulose synthesis regulation mechanisms, see, Wang et al. (2016), Kesten et al. (2017), and Polko and Kieber (2019).

\section{Non-CESA proteins implicated in cellulose synthesis}

Many genetic screens and $\mathrm{Y} 2 \mathrm{H}$ assays enabled to identify several non-CESA proteins essential for cellulose synthesis in Arabidopsis including CHITINASE-LIKE1/ POM-POM1 (At1g05850), COBRA (At5g60920), KOBITO1 (At3g08550), KORRIGAN1 (At5g49720), and above mentioned POM2/CSI1 (At2g22125) (Hauser et al. 1995, Nicol et al. 1998, Schindelman et al. 2001, Pagant et al. 2002, Gu et al. 2010, Sánchez-Rodriguez et al. 2012) (Fig. 2). Among them, two last ones have so far been found to be directly associated with CESAs (Li et al. 2012, Vain et al. 2014). The growth phenotypes observed in corresponding mutants are reminiscent of the phenotype of cellulose-deficient mutants with elongation defects or WT plants cultivated in presence of cellulose synthesisblocking herbicides. Reduced elongation in these mutants is interpreted as a result of the loss of growth anisotropy due to the absence of the scaffold of ordered CMFs that constrain directional growth. Moreover, genes encoding non-CESA proteins are co-expressed with PCW CESAs (Persson et al. 2005).

KORRIGAN1 (KOR1) is the most studied member of KOR family belonging to endo-1,4- $\beta$-D-glucanases (cellulases) (Nicol et al. 1998). KORRIGAN1 exhibits substrate specificity for amorphous cellulose and lowsubstituted carboxymethyl cellulose but not for crystalline cellulose or xyloglucans (Mølhøj et al. 2001). Interestingly, although its substrate is synthesized at the PM, KOR1 was

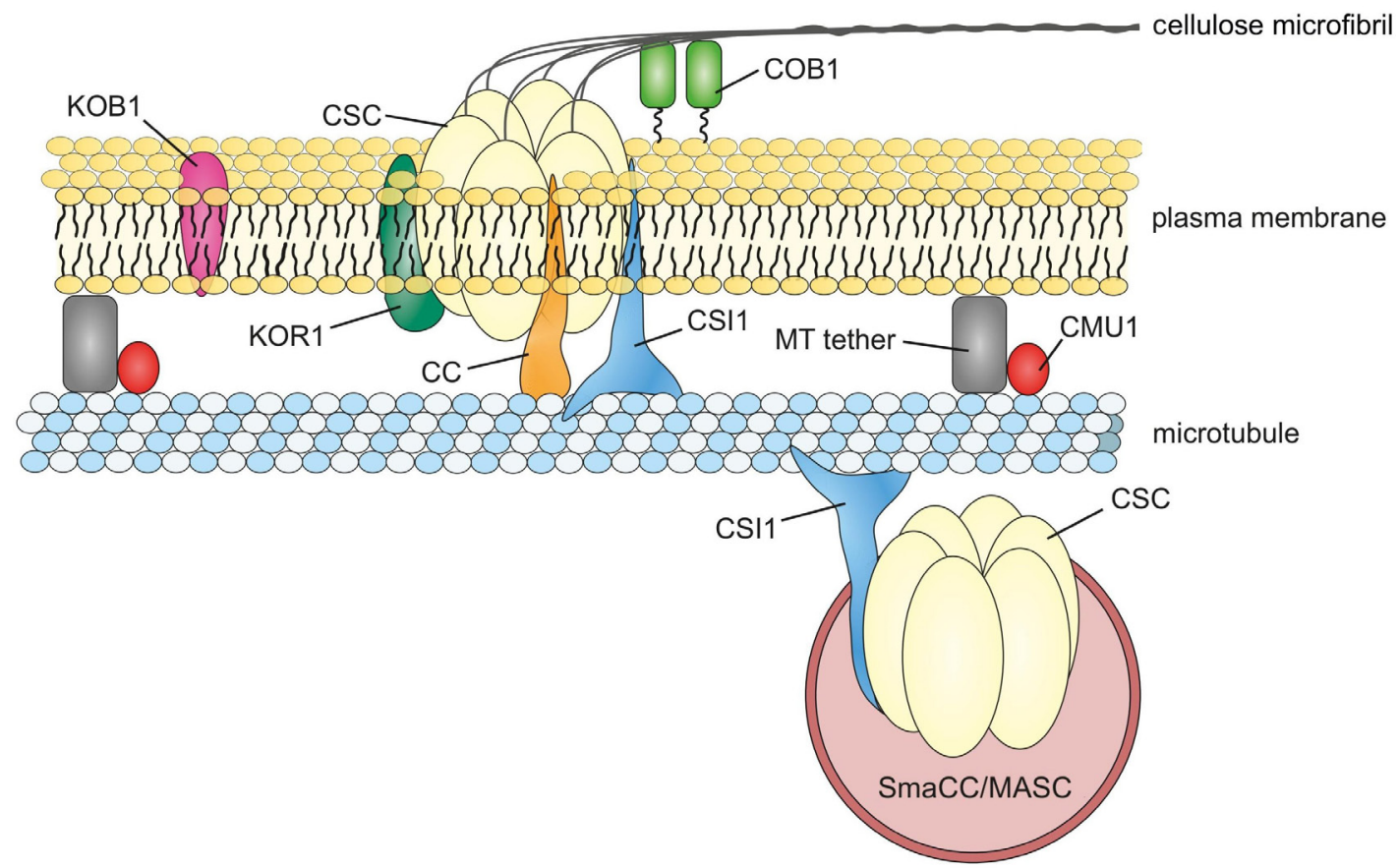

Fig. 2. A schematic representation of the plasma membrane-inserted cellulose synthase complex (CSC), its connection with a microtubule (MT), as well as some other membrane-bound proteins involved in cellulose synthesis and/or regulation. The scheme also illustrates a CSC internalized into the cell cortex in a vesicle called the small subcellular CESA-containing compartment or microtubule-associated CESA compartment (SmaCC/MASC). CC - COMPANION OF CELLULOSE SYNTHASE, CMU1 - CELLULOSE SYNTHASEMICROTUBULE UNCOUPLING1, COB1 - COBRA1, CSI1 - CELLULOSE SYNTHASE-INTERACTIVE1, KOB1 - KOBITO1, KOR1 - KORRIGAN1. 
shown to cycle through different intracellular compartments including Golgi stacks, post-Golgi compartments, SmaCCs/MASCs, prevacuolar compartments, vacuole, and through the PM (Robert et al. 2005, Vain et al. 2014). The KORI mutants are characterized by cellulose synthesis defects including seedling lethality with cytokinesis aberrations (kor1-2) (Zuo et al. 2000), dwarfism and radial swelling in roots (korl-1 and -3, rsw2 alleles) (Nicol et al. 1998, Lane et al. 2001), and collapsed xylem (irx 2-1 and -2) (Szyjanowicz et al. 2004). Despite numerous studies indicating its role in both PCW and SCW cellulose synthesis, precise function of KOR1 is not understood. KORRIGAN1 may determine the length of growing glucan chains and/or release the CMF once it was incorporated into the wall. Alternatively, KOR1 may hydrolyze and remove disordered and aberrantly associated cellulose chains to relieve tensions arisen during CMF emergence/assembly (Newman et al. 2013). Y2H, life cell imaging and BiFC showed that GFP-KOR1 co-localized with all PCW CESA proteins in the PM and constitutes an integral part of CSC, however, the interactions between CESAs and KOR1 are more unstable than those among CESAs themselves (Vain et al. 2014). Indeed, the co-immunoprecipitation experiments showed a stable interaction existed between CESA3 and CESA6 in Triton $X$-100-solubilized protein extracts whereas KOR1 did not stably interact with CESAs in these detergent-solubilized extracts (Desprez et al. 2007). In SCW CSCs, KOR1 was shown to interact only with CESA4 and CESA8 (Mansoori et al. 2014). In addition, Vain et al. (2014) showed that GFP-KOR1 moved in PM along linear trajectories defined by CMTs with a velocity similar to that of GFP-tagged CESAs and that upon treatment with oryzalin, a MT-depolymerizing drug, the trajectories of both particles GFP-KOR1 and GFP-CESA3 were disorganized in a comparable manner. In kor 1-1, the velocity of GFP-CESA3 in the PM was reduced in comparison with WT, indicating that KOR1 is necessary for the movement of CSCs. In the presence of cellulose synthesis inhibitors, GFP-KOR1 is, similarly to CSC, internalized into SmaCCs/MASCs (Robert et al. 2005, Vain et al. 2014). This implies that KOR1 may indeed cleave glucan chains to detach CSC from the CW-bound $\mathrm{CMF}$ before internalization of the complex. Moreover, in the korl-1 background, the removal of GFP-CESA3 signals from the PM to SmaCCs/MASCs upon CGA $325^{\prime} 615$ treatment was significantly reduced in opposition to WT, showing that KOR1 is required for the intracellular trafficking of the CSCs (Vain et al. 2014).

CHITINASE-LIKE1/POM-POM1 (CTL1/POM1) was identified in a 'conditional root expansion' screen for abnormal root expansion and its deficiency induces lower cellulose content, impaired CW rigidity and root swelling (Hauser et al. 1995). The CTL1/POM1 was detected with Golgi-localized CESAs and SmaCCs/MASCs (SánchezRodriguez et al. 2012). Together with its close homolog CTL2, CTL1/POM1 is secreted to the apoplast and participates in cellulose assembly and interactions with hemicelluloses. The authors measured slower velocity of CSCs in the PM of elongating ctll-1 hypocotyls than in the WT ones resulting in reduced cellulose content.
COBRA $(C O B)$ belongs to genes that are the most highly co-expressed with PCW CESAs (Persson et al. 2005). It encodes a plant-specific, extracellular glycosylphosphatidylinositol-anchored membrane protein (Schindelman et al. 2001). Cobral was identified in a screen for cell expansion regulators with a root-specific and conditional cell expansion defect (Benfey et al. 1993). COB-deficient plants are characterized by the loss of anisotropic expansion in rapidly developing organs, disordered orientation of CMFs and reduced crystalline cellulose content (Roudier et al. 2005). The authors detected $\mathrm{COB}$ in the Golgi, PM, and within PCW. Moreover, COB was specifically found in elongating cells and distributed in a banding pattern, parallel to CMTs, indicating its putative involvement in the control of the CSCs movement and oriented deposition of CMFs (Roudier et al. 2005). Both genetic approach and oryzalin treatment showed that COB distribution at the surface of elongating root cells was dependent on the CMT organization. At the onset of cell elongation, $\mathrm{COB}$ was detected in the cytosol and at the cell periphery while during the elongation phase $\mathrm{COB}$ was organized in narrow bands perpendicular to the longitudinal axis.

KOBITO1 (KOB1) is another plant-specific protein involved in CMF deposition in elongating cells (Pagant et al. 2002). The kobl mutant is a cellulose-deficient, severely dwarfed mutant developing short and swollen dark-grown hypocotyl, short root and reduced apical hook. CMFs in kobl are randomly oriented only in elongating cells where incomplete CWs are also visible indicating that the protein may coordinate cellulose synthesis and rapid cell expansion (Pagant et al. 2002). Similar CW gaps occur in WT seedlings treated with cellulose synthesis inhibitors. GFP-KOB1 fusion protein was detected at the cell surface of growing epidermal and cortical cells in contrast to dividing cells where the signal was visible in the cytoplasm. Lertpiriyapong and Sung (2003) identified two mutant genes causing strong growth phenotype that are allelic to kobl, and named them eld1 (elongation defective1). Interestingly, the ELD1-GFP signal was detected in CWs, rather than PM, indicating that ELD1/ $\mathrm{KOB} 1$ is a secreted protein participating in cell growth promotion.

\section{The connection between microtubules and cellulose synthase complex}

Plant MTs are characterized by a greater intrinsic dynamicity than the animal ones (Shaw et al. 2003) reflecting probably the necessity to cope with changing environment in place. Highly dynamic arrays of CMTs are necessary for plant growth since they influence the $\mathrm{CW}$ material anisotropy that is the basis of cell elongation. In elongating cells, CMFs are transversely oriented and promote longitudinal cell expansion. CMTs serve as templates and guide the deposition of CMFs resulting in particular wall texture and effects of cell shape and size (Gardiner et al. 2003). CMTs change their orientation in response to a variety of signals like irradiance, gravity, or hormones (Chen et al. 2016) 
but they also undergo cyclic rotary movements associated with cell growth that explain the changes of CMF angle in consecutive layers of the polylamellate $\mathrm{CW}$ (Chan et al. 2007). The reorientation of CMTs occurs conjointly with a reorientation of the CSCs trajectories; in consequence, the orientation of nascent CMFs changes accordingly (Paredez et al. 2006, Chan et al. 2010). Paredez et al. (2006) confirmed the functional association between PM-inserted CESAs and CMTs. The authors showed that CESAs move along the surface of the PM, presumably driven forward by the deposition of cellulose chains, and along linear trajectories overlaying with CMTs. In addition to orienting their trajectories, CSCs are positioned into the PM at sites determined by CMTs (Crowell et al. 2009, Gutierrez et al. 2009). Chan et al. (2010) showed that MTdepolymerizing or stabilizing drugs, oryzalin and taxol respectively, blocked the rotation of CESA tracks. As a result, higher variability in CMFs orientation altered the polylamellate CW texture in epidermal cells of Arabidopsis hypocotyls. The disruption of CMTs transiently impair the distribution of CSCs at the PM but neither the rate of CSCs insertion nor their velocity is affected proving that CMTs are required for the guidance and not the movement of CSCs per se (Paredez et al. 2006, Gutierrez et al. 2009, Chan et al. 2010). Similarly, during SCW deposition in Arabidopsis CSC tracks are disorganized after oryzalin treatment in protoxylem tracheary cells showing that MTs are important for SCW banding pattern (Watanabe et al. 2015). In contrast, they are not required either for CSC delivery to the PM or for the CSC velocity. Interestingly, as shown by the treatment with cellulose synthesis inhibitors that induce reorientation of MTs in Arabidopsis root cells, the organization of CMTs can be also influenced by cellulose biosynthesis (Paredez et al. 2008, Peng et al. 2013). Similarly, PCW mutants affected in cellulose biosynthesis exhibit changes in MT organization (Paredez et al. 2008). Finally, a very important finding on the control of CSC movement was provided by Liu et al. (2016) who identified a family of proteins responsible for lateral stability of CMTs in growing Arabidopsis seedlings. Cellulose synthase-microtubule uncoupling (CMU) proteins, distributed along the MTs as immobile puncta, are necessary for CMTs to withstand forces generated by the motile CSCs and to direct cellulose deposition during anisotropic cell growth. CMU-deficient seedlings show lateral MT displacement and affected MT-based guidance of CSC movement resulting in a cell twisting phenotype in etiolated hypocotyls.

The interactions between CSCs and CMTs are mediated by a CESA-interacting protein named POM2/ CSI1, identified in a $\mathrm{Y} 2 \mathrm{H}$ screen using CESA6 catalytic domain as bait (Gu et al. 2010). POM2/CSI1 is essential for CESA movement along the PM surface and functions as a molecular bridge between CSCs and CMTs (Fig. 2). Although POM2/CSI1 does not share any sequence homology with structural MT-associated proteins, Li et al. (2012) pelleted POM2/CSI1 with polymerized tubulin and proved that POM2/CSI1 is a MT-binding protein. POM2/CSI1 encodes a large (2 151 aa) plant-specific protein containing several motifs necessary for protein- protein interactions. POM2/CSI1 interacts directly with CESA 1,3 , and 6 and it is the first identified non-CESA protein associated with CSC. In vivo, FP-POM2/CSI1 colocalizes with GFP-CESA3 or GFP-CESA6 in the PM but does not label any Golgi-associated CESAs indicating that POM2/CSI1 interacts with the CSC only upon arrival at the PM (Gu et al. 2010). The loss-of-function pom $2 /$ csil mutant is characterized by reduced cellulose content by $50 \%$ in respect to WT and shorter and swollen roots and hypocotyls as a result of defects in control of anisotropic expansion ( $\mathrm{Gu}$ et al. 2010). POM2/CSI1-deficient plants not only show an abnormal distribution of CSCs but their trajectories move independently of the direction of the underlying CMTs (Bringmann et al. 2012, Lei et al. 2012). Moreover, the velocities of CESAs are reduced in POM2/ CSI1-deficient plants to a similar extent as in oryzalintreated plants (Gu et al. 2010, Li et al. 2012). Two POM2/ CSI1-like proteins, namely CSI2 and CSI3, are encoded by Arabidopsis genome but in contrast to pom $2 / \mathrm{csil}$ mutant, single and double knock-outs in CSI2 and CSI3 do not show any growth deficiencies (Bringmann et al. 2012).

Two plant-specific proteins, COMPANION OF CELLULOSE SYNTHASE1 and 2 (CC1 and CC2), were shown to protect CSC activity by sustaining MT dynamics during salt stress (Endler et al. 2015) (Fig. 2). CC1 is coexpressed with PCW CESAs and induced by salinity. Single and double mutants do not show any changes in growth phenotype under control conditions. In contrast, under salt stress the sensitivity of the $c c 1 c c 2$ seedlings is manifested by strongly reduced hypocotyl elongation in darkness and low cellulose content indicating the functional redundancy between the two proteins. The $C C 1$ and $C C 2$ genes are members of a four-member gene family in Arabidopsis but only $C C 1$ and $C C 2$ are crucial for cellulose synthesis and seedling development under unfavorable conditions (Endler et al. 2015). Dual-labelled GFP-CC1 (or GFP$\mathrm{CC} 2$ ) and tdTomato-CesA6 lines tracking revealed that the CSCs and CC proteins move together through the $\mathrm{PM}$ under control conditions hence the name of this gene family (Endler et al. 2015). What is more, Y2H test enabled to establish direct interactions between CESA1, 3, and 6 and $\mathrm{CC} 1$. Similarly to CESAs, the movement of FP-CC1 and $\mathrm{CC} 2$ co-aligned with the CMT array. Interestingly, GFP-CC1 signal is lost in isoxaben-treated specimens and tracks to SmaCCs/MASCs, where the CC proteins are relocated along with CESAs in response to the treatment (Fig. 2). Osmotic stress was also shown to change the distribution of CSCs by inducing their return to SmaCCs/ MASCs and to diminish the rate of cellulose biosynthesis (Paredez et al. 2006, Gutierrez et al. 2009). Indeed, upon salt stress exposure, MTs depolymerize gradually but they re-polymerize under prolonged stress as a result of adaptation (Wang et al. 2007). In the $c c 1 c c 2$ mutants the MTs take longer to reassemble and their arrangement is unstable (Endler et al. 2015). Consecutively, cellulose biosynthesis in not restored in the double knockout mutant. The authors speculate that CCs play a crucial role in the reassembly and maintenance of the MT stability and protect CESA activity during long-term ionic stress (Endler et al. 2015). The CCs are transmembrane proteins with the 
CESA-associated $\mathrm{C}$ terminus located in the apoplastic region and the MT-bound N-terminal domain. The $\mathrm{N}$-terminal domain stimulates MT formation enabling the CMT array re-emergence after ionic stress (Endler et al. 2015). The newly established MT network allows CSCs to be re-inserted into the PM and, in effect, the resumption of cellulose synthesis.

\section{Concluding remarks}

In recent years, a remarkable progress has been achieved in our understanding of many aspects of the cellulose-synthesizing machinery in higher plants. Latest measurements of the CSC lobes and the size of elementary CMFs support 18-CESA complex model. Smaller than algal microfibrils, 18-chain microfibrils may reflect an adaptive trait of land plants enabling more possibilities for CMF assembly, controlling architectural features of CWs. Mutant analysis demonstrated the requirement of different CESA isoforms to form a functional complex. Finally, the identification of novel non-CESA proteins involved in cellulose synthesis and regulation, especially the CSC trafficking and the MT-based guidance of CSC movements, unraveled the complexity and dynamics of cellulose production during growth and development, as well as in response to various environmental conditions. Future challenges are to discover additional regulatory mechanisms like the post-translational CESA modifications, including the functions of the kinases involved in CESA phosphorylation, or mechanisms responsible for $\mathrm{CW}$ integrity and remodeling control. The roles of numerous receptor-like kinases in CW sensing and feedback signaling are extensively studied and represent an exciting field in current plant cell wall research.

\section{References}

Amor, Y., Haigler, C.H., Johnson, S., Wainscott, M., Delmer, D.P.: A membrane-associated form of sucrose synthase and its potential role in synthesis of cellulose and callose in plants. Proc. nat. Acad. Sci. USA 92: 9353-9357, 1995.

Appenzeller, L., Doblin, M., Barreiro, R., Wang, H., Niu, X., Kollipara, K., Carrigan, L., Tomes, D., Chapman, M., Dhugga, K.S.: Cellulose synthesis in maize: isolation and expression analysis of the cellulose synthase (CesA) gene family. - Cellulose 11: 287-299, 2004.

Arioli, T., Peng, L., Betzner, A.S., Burn, J., Wittke, W., Herth, W., Camilleri, C., Höfte, H., Plazinski, J., Birch, R., Cork, A., Glover, J., Redmond, J., Williamson, R.E.: Molecular analysis of cellulose biosynthesis in Arabidopsis. - Science 279: 717$720,1998$.

Atanassov, I.I., Pittman, J.K., Turner, S.R.: Elucidating the mechanisms of assembly and subunit interaction of the cellulose synthase complex of Arabidopsis secondary cell walls. - J. biol. Chem. 284: 3833-3841, 2009.

Bashline, L., Li, S., Anderson, C.T., Lei, L., Gu, Y.: The endocytosis of cellulose synthase in Arabidopsis is dependent on $\mu 2$, a clathrin-mediated endocytosis adaptin. - Plant Physiol. 163: 150-160, 2013.

Bashline, L., Li, S., Zhu, X., Gu, Y.: The TWD40-2 protein and the
AP2 complex cooperate in the clathrin-mediated endocytosis of cellulose synthase to regulate cellulose biosynthesis. - Proc. nat. Acad. Sci. USA 112: 12870-12875, 2015.

Benfey, P.N., Linstead, P.J., Roberts, K., Schiefelbein, J.W., Hauser, M.T., Aeschbacher, R.A.: Root development in Arabidopsis: four mutants with dramatically altered root morphogenesis. - Development 119: 57-70, 1993.

Birnbaum, K., Shasha, D.E., Wang, J.Y., Jung, J.W., Lambert, G.M., Galbraith, D.W., Benfey, P.N.: A gene expression map of the Arabidopsis root. - Science 302: 1956-1960, 2003.

Bischoff, V., Desprez, T., Mouille, G., Vernhettes, S., Gonneau, M., Höfte, H.: Phytochrome regulation of cellulose synthesis in Arabidopsis. - Curr. Biol. 21: 1822-1827, 2011.

Bowling, A.J., Brown, R.M., Jr.: The cytoplasmic domain of the cellulose-synthesizing complex in vascular plants. Protoplasma 233: 115-127, 2008.

Bringmann, M., Li, E., Sampathkumar, A., Kocabek, T., Hauser, M.T., Persson, S.: POM-POM2/CELLULOSE SYNTHASE INTERACTING1 is essential for the functional association of cellulose synthase and microtubules in Arabidopsis. - Plant Cell 24: 163-177, 2012.

Brown, D.M., Zeef, L.A.H., Ellis, J., Goodacre, R., Turner, S.R.: Identification of novel genes in Arabidopsis involved in secondary cell wall formation using expression profiling and reverse genetics. - Plant Cell 17: 2281-2295, 2005.

Burton, R.A., Shirley, N.J., King, B.J., Harvey, A.J., Fincher, G.B.: The CesA gene family of barley. Quantitative analysis of transcripts reveals two groups of co-expressed genes. Plant Physiol. 134: 224-236, 2004.

Caño-Delgado, A., Penfield, S., Smith, C., Catley, M., Bevan, M.: Reduced cellulose synthesis invokes lignification and defense responses in Arabidopsis thaliana. - Plant J. 34: 351362, 2003.

Carroll, A., Mansoori, N., Li, S., Lei, L., Vernhettes, S., Visser, R.G., Somerville, C., Gu, Y., Trindade, L.M.: Complexes with mixed primary and secondary cellulose synthases are functional in Arabidopsis plants. - Plant Physiol. 160: 726737, 2012

Carroll, A., Specht, C.D.: Understanding plant cellulose synthases through a comprehensive investigation of the cellulose synthase family sequences. - Front. Plant Sci. 2: 5, 2011.

Chan, J., Calder, G., Fox, S., Lloyd, C.: Cortical microtubule arrays undergo rotary movements in Arabidopsis hypocotyl epidermal cells. - Nat. cell. Biol. 9: 171-175, 2007.

Chan, J., Crowell, E., Eder, M., Calder, G., Bunnewell, S., Findlay, K., Vernhettes, S., Höfte, H., Lloyd, C.: The rotation of cellulose synthase trajectories is microtubule dependent and influences the texture of epidermal cell walls in Arabidopsis hypocotyls. - J. Cell Sci. 123: 3490-3495, 2010.

Chanzy, H., Imada, K., Mollard, A., Vuong, R., Barnoud, F.: Crystallographic aspects of sub-elementary cellulose fibrils occurring in the wall of rose cells cultured in vitro. Protoplasma 100: 303-316, 1979.

Chanzy, H., Imada, K., Vuong, R.: Electron diffraction from the primary wall of cotton fibers. - Protoplasma 94: 299-306, 1978.

Chen, S., Ehrhardt, D.W., Somerville, C.R.: Mutations of cellulose synthase (CESA1) phosphorylation sites modulate anisotropic cell expansion and bidirectional mobility of cellulose synthase. - Proc. nat. Acad. Sci. USA 107: 1718817193, 2010.

Chen, X., Wu, S., Liu, Z., Friml, J.: Environmental and endogenous control of cortical microtubule orientation. Trends cell. Biol. 26: 409-419, 2016.

Cifuentes, C., Bulone, V., Emons, A.M.: Biosynthesis of callose and cellulose by detergent extracts of tobacco cell membranes 
and quantification of the polymers synthesized in vitro. - J. integr. Plant Biol. 52: 221-233, 2010.

Crowell, E.F., Bischoff, V., Desprez, T., Rolland, A., Stierhof, Y.D., Schumacher, K., Gonneau, M., Höfte, H., Vernhettes, S.: Pausing of Golgi bodies on microtubules regulates secretion of cellulose synthase complexes in Arabidopsis. - Plant Cell 21: 1141-1154, 2009.

Delmer, D.P.: Cellulose biosynthesis: exciting times for a difficult field of study. - Annu. Rev. Plant Physiol. Plant mol. Biol. 50: 245-276, 1999.

Desprez, T., Juraniec, M., Crowell, E.F., Jouy, H., Pochylova, Z., Parcy, F., Höfte, H., Gonneau, M., Vernhettes, S.: Organization of cellulose synthase complexes involved in primary cell wall synthesis in Arabidopsis thaliana. - Proc. nat. Acad. Sci. USA 104: 15572-15577, 2007.

Ding, S.Y., Himmel, M.E.: The maize primary cell wall microfibril: a new model derived from direct visualization. J. Agr. Food Chem. 54: 597-606, 2006.

Djerbi, S., Lindskog, M., Arvestad, L., Sterky, F., Teeri, T.T.: The genome sequence of black cottonwood (Populus trichocarpa) reveals 18 conserved cellulose synthase ( $\operatorname{Ces} A)$ genes. - Planta 221: 739-746, 2005.

Doblin, M.S., Kurek, I., Jacob-Wilk, D., Delmer, D.P.: Cellulose biosynthesis in plants: from genes to rosettes. - Plant Cell Physiol. 43: 1407-1420, 2002.

Donaldson, L.: Cellulose microfibril aggregates and their size variation with cell wall type. - Wood Sci. Technol. 41: 443460, 2007.

Endler, A., Kesten, C., Schneider, R., Zhang, Y., Ivakov, A., Froehlich, A., Funke, N., Persson, S.: A mechanism for sustained cellulose synthesis during salt stress. - Cell 162: 1353-1364, 2015.

Eskandari, S., Wright, E.M., Kreman, M., Starace, D.M., Zampighi, G.A.: Structural analysis of cloned plasma membrane proteins by freeze-fracture electron microscopy. Proc. nat. Acad. Sci. USA 95: 11235-11240, 1998.

Facette, M.R., Shen, Z., Björnsdóttir, F.R., Briggs, S.P., Smith, L.G.: Parallel proteomic and phosphoproteomic analyses of successive stages of maize leaf development. - Plant Cell 25: 2798-2812, 2013.

Fagard, M., Desnos, T., Desprez, T., Goubet, F., Refregier, G., Mouille, G., McCann, M., Rayon, C., Vernhettes, S., Höfte, H.: PROCUSTE1 encodes a cellulose synthase required for normal cell elongation specifically in roots and dark-grown hypocotyls of Arabidopsis. - Plant Cell 12: 2409-2424, 2000.

Fernandes, A.N., Thomas, L.H., Altaner, C.M., Callow, P., Forsyth, V.T., Apperley, D.C., Kennedy, C.J., Jarvis, M.C.: Nanostructure of cellulose microfibrils in spruce wood. Proc. nat. Acad. Sci. USA 108: E1195-E1203, 2011.

Gardiner, J.C., Taylor, N.G., Turner, S.R.: Control of cellulose synthase complex localization in developing xylem. - Plant Cell 15: 1740-1748, 2003

Gonneau, M., Desprez, T., Guillot, A., Vernhettes, S., Höfte, H.: Catalytic subunit stoichiometry within the cellulose synthase complex. - Plant Physiol. 166: 1709-1712, 2014.

Gu, Y., Kaplinsky, N., Bringmann, M., Cobb, A., Carroll, A., Sampathkumar, A., Baskin, T.I., Persson, S., Somerville, C.R.: Identification of a cellulose synthase-associated protein required for cellulose biosynthesis. - Proc. nat. Acad. Sci. USA 107: 12866-12871, 2010.

Gutierrez, R., Lindeboom, J.J., Paredez, A.R., Emons, A.M., Ehrhardt, D.W.: Arabidopsis cortical microtubules position cellulose synthase delivery to the plasma membrane and interact with cellulose synthase trafficking compartments. Nat. Cell Biol. 11: 797-806, 2009.

Ha, M.A., Apperley, D.C., Evans, B.W., Huxham, I.M., Jardine,
W.G., Viëtor, R.J., Reis, D., Vian, B., Jarvis, M.C.: Fine structure in cellulose microfibrils: NMR evidence from onion and quince. - Plant J. 16: 183-190, 1998.

Haigler, C.H., Brown, R.M.: Transport of rosettes from the Golgi apparatus to the plasma membrane in isolated mesophyll cells of Zinnia elegans during differentiation to tracheary elements in suspension culture. - Protoplasma 134: 111-120, 1986.

Hauser, M.T., Morikami, A., Benfey P.N.: Conditional root expansion mutants of Arabidopsis. - Development 121: 1237$1252,1995$.

Herth, W.: Arrays of plasma-membrane 'rosettes' involved in cellulose microfibril formation of Spirogyra. - Planta 159: 347-356, 1983.

Hill, J.L., Jr., Hammudi, M.B., Tien, M.: The Arabidopsis cellulose synthase complex: a proposed hexamer of CESA trimers in an equimolar stoichiometry. - Plant Cell 26: 48344842, 2014.

Hill, J.L., Jr., Hill, A.N., Roberts, A.W., Haigler, C.H., Tien, M.: Domain swaps of Arabidopsis secondary wall cellulose synthases to elucidate their class specificity. - Plant Direct 2: e00061, 2018.

Kennedy, C.J., Cameron, G.J., Šturcová, A., Apperley, D.C., Altaner, C., Wess, T.J., Jarvis, M.C.: Microfibril diameter in celery collenchyma cellulose: X-ray scattering and NMR evidence. - Cellulose 14: 235-246, 2007.

Kerstens, S., Verbelen, J.P.: Cellulose orientation at the surface of the Arabidopsis seedling. Implications for the biomechanics in plant development. - J. Struct. Biol. 144: 262-270, 2003.

Kesten, C., Menna, A., Sánchez-Rodríguez, C.: Regulation of cellulose synthesis in response to stress. - Curr. Opin. Plant Biol. 40: 106-113, 2017.

Kim, W.C., Ko, J.H., Han, K.H.: Identification of a cisacting regulatory motif recognized by MYB46, a master transcriptional regulator of secondary wall biosynthesis. Plant mol. Biol. 78: 489-501, 2012.

Kim, W.C., Ko, J.H., Kim, J.Y., Kim, J., Bae, H.J., Han, K.H.: MYB46 directly regulates the gene expression of secondary wall-associated cellulose synthases in Arabidopsis. - Plant J. 73: 26-36, 2013.

Kimura, S., Laosinchai, W., Itoh, T., Cui, X., Linder, C.R., Brown, R.M.: Immunogold labeling of rosette terminal cellulose-synthesizing complexes in the vascular plant Vigna angularis. - Plant Cell 11: 2075-2086, 1999.

Ko, J.H., Kim, W.C., Han, K.H.: Ectopic expression of MYB46 identifies transcriptional regulatory genes involved in secondary wall biosynthesis in Arabidopsis. - Plant J. 60: 649-665, 2009.

Kudlicka, K., Brown, R.M. Jr.: Cellulose and callose biosynthesis in higher plants. I. solubilization and separation of $(1 \rightarrow 3)$ and $(1 \rightarrow 4)-\beta$-glucan synthase activities from mung bean. Plant Physiol. 115: 643-656, 1997.

Kurek, I., Kawagoe, Y., Jacob-Wilk, D., Doblin, M., Delmer D.: Dimerization of cotton fiber cellulose synthase catalytic subunits occurs via oxidation of the zinc-binding domains. Proc. nat. Acad. Sci. USA 99: 11109-11114, 2002.

Lai-Kee-Him, J., Chanzy, H., Müller, M., Putaux, J.L., Imai, T., Bulone, V.: In vitro versus in vivo cellulose microfibrils from plant primary wall synthases: structural differences. - J. biol. Chem. 277: 36931-36939, 2002.

Lane, D.R., Wiedemeier, A., Peng, L., Höfte, H., Vernhettes, S., Desprez, T., Hocart, C.H., Birch, R.J., Baskin, T.I., Burn, J.E., Arioli, T., Betzner, A.S., Williamson, R.E.: Temperaturesensitive alleles of RSW2 link the KORRIGAN endo$1,4-\beta$-glucanase to cellulose synthesis and cytokinesis in Arabidopsis. - Plant Physiol. 126: 278-288, 2001.

Lei, L., Li, S., Gu, Y.: Cellulose synthase interactive protein 1 
(CSI1) mediates the intimate relationship between cellulose microfibrils and cortical microtubules. - Plant Signal. Behav. 7: 1-5, 2012

Lei, L., Singh, A., Bashline, L., Shundai, Li., Yingling, Y.G., Gu, Y.: CELLULOSE SYNTHASE INTERACTIVE1 is required for fast recycling of cellulose synthase complexes to the plasma membrane in Arabidopsis. - Plant Cell 27: 2926-2940, 2015.

Lertpiriyapong, K., Sung, Z.R.: The elongation defective1 mutant of Arabidopsis is impaired in the gene encoding a serine-rich protein. - Plant mol. Biol. 53: 581-595, 2003.

Li, S., Lei, L., Gu, Y.: Functional analysis of complexes with mixed primary and secondary cellulose synthases. - Plant Signal. Behav. 8: e23179, 2013.

Li, S., Lei, L., Somerville, C.R., Gu, Y.: Cellulose synthase interactive protein 1 (CSI1) links microtubules and cellulose synthase complexes. - Proc. nat. Acad. Sci. USA 109: 185190, 2012.

Lin, F.C., Brown, R.M., Jr., Drake, R.R., Jr., Haley, B.E.: Identification of the uridine 5'-diphosphoglucose (UDP-Glc) binding subunit of cellulose synthase in Acetobacter xylinum using the photoaffinity probe 5-azido-UDP-Glc. - J. biol. Chem. 265: 4782-4784, 1990.

Little, A., Schwerdt, J.G., Shirley, N.J., Khor, S.F., Neumann, K., O’Donovan, L.A., Lahnstein, J., Collins, H.M., Henderson, M., Fincher, G.B., Burton, R.A.: Revised phylogeny of the cellulose synthase gene superfamily: insights into cell wall evolution. - Plant Physiol. 177: 1124-1141, 2018.

Liu, Z., Schneider, R., Kesten, C., Zhang, Y., Somssich, M., Zhang, Y., Fernie, A.R., Persson, S.: Cellulose-microtubule uncoupling proteins prevent lateral displacement of microtubules during cellulose synthesis in Arabidopsis. - Dev. Cell 38: 305-315, 2016.

Mansoori, N., Timmers, J., Desprez, T., Kamei, C.L.A., Dees, D.C.T., Vincken, J.P., Visser, R.G.F., Hofte, H., Vernhettes, S., Trindade, L.M.: KORRIGAN1 interacts specifically with integral components of the cellulose synthase machinery. Plos ONE 9: e112387, 2014.

McCarthy, R.L., Zhong, R., Ye, Z.H.: MYB83 is a direct target of SND1 and acts redundantly with MYB46 in the regulation of secondary cell wall biosynthesis in Arabidopsis. - Plant Cell Physiol. 50: 1950-1964, 2009.

Miart, F., Desprez, T., Biot, E., Morin, H., Belcram, K., Höfte, H., Gonneau, M., Vernhettes, S.: Spatio-temporal analysis of cellulose synthesis during cell plate formation in Arabidopsis. - Plant J. 77: 71-84, 2014

Morgan, J.L., Strumillo, J., Zimmer, J.: Crystallographic snapshot of cellulose synthesis and membrane translocation. - Nature 493: 181-186, 2013.

Mølhøj, M., Ulvskov, P., Dal Degan, F.: Characterization of a functional soluble form of a Brassica napus membraneanchored endo-1,4- $\beta$-glucanase heterologously expressed in Pichia pastoris. - Plant Physiol. 127: 674-684, 2001.

Mueller, S.C., Brown, R.M.: Evidence for an intramembrane component associated with a cellulose microfibrilsynthesizing complex in higher plants. - J. Cell Biol. 84: 315326, 1980.

Nairn, C.J., Haselkorn, T.: Three loblolly pine CesA genes expressed in developing xylem are orthologous to secondary cell wall CesA genes of angiosperms. - New Phytol. 166: 907 915, 2005.

Nakagami, H., Sugiyama, N., Mochida, K., Daudi, A., Yoshida, Y., Toyoda, T., Tomita, M., Ishihama, Y., Shirasu, K.: Largescale comparative phosphoproteomics identifies conserved phosphorylation sites in plants. - Plant Physiol. 153: 11611174, 2010.
Newman, R.H., Hill, S.J., Harris, P.J.: Wide-angle X-ray scattering and solid-state nuclear magnetic resonance data combined to test models for cellulose microfibrils in mung bean cell walls. - Plant Physiol. 163: 1558-1567, 2013.

Nicol, F., His, I., Jauneau, A., Vernhettes, S., Canut, H., Höfte, H.: A plasma membrane-bound putative endo-1,4- $\beta$-D-glucanase is required for normal wall assembly and cell elongation in Arabidopsis. - EMBO J. 17: 5563-5576, 1998.

Nixon, B.T., Mansouri, K., Singh, A., Du, J., Davis, J.K., Lee, J.G., Slabaugh, E., Vandavasi, V.G., O’Neill, H., Roberts, E.M., Roberts, A.W., Yingling, Y.G., Haigler, C.H.: Comparative structural and computational analysis supports eighteen cellulose synthases in the plant cellulose synthesis complex. - Sci. Rep. 6: 28696, 2016.

Nobles, D.R., Romanovicz, D.K., Brown, R.M., Jr.: Cellulose in cyanobacteria. Origin of vascular plant cellulose synthase? Plant Physiol. 127: 529-542, 2001.

Nühse, T.S., Stensballe, A., Jensen, O.N., Peck, S.C.: Largescale analysis of in vivo phosphorylated membrane proteins by immobilized metal ion affinity chromatography and mass spectrometry. - Mol. Cell. Proteomics 2: 1234-1243, 2003.

Oehme, D.P., Downton, M.T., Doblin, M.S., Wagner, J., Gidley, M.J., Bacic, A.: Unique aspects of the structure and dynamics of elementary I $\beta$ cellulose microfibrils revealed by computational simulations. - Plant Physiol. 168: 3-17, 2015.

Pagant, S., Bichet, A., Sugimoto, K., Lerouxel, O., Desprez, T., McCann, M., Lerouge, P., Vernhettes, S., Höfte, H.: KOBITO1 encodes a novel plasma membrane protein necessary for normal synthesis of cellulose during cell expansion in Arabidopsis. - Plant Cell 14: 2001-2013, 2002.

Paredez, A.R., Persson, S., Ehrhardt, D.W., Somerville, C.R.: Genetic evidence that cellulose synthase activity influences microtubule cortical array organization. - Plant Physiol. 147: 1723-1434, 2008.

Paredez, A.R., Somerville, C.R., Ehrhardt, D.W.: Visualization of cellulose synthase demonstrates functional association with microtubules. - Science 312: 1491-1495, 2006.

Pear, J.R., Kawagoe, Y., Schreckengost, W.E., Delmer, D.P., Stalker D.M.: Higher plants contain homologs of the bacterial celA genes encoding the catalytic subunit of cellulose synthase. - Proc. nat. Acad. Sci. USA 93: 12637-12642, 1996.

Peng, L., Xiang, F., Roberts, E., Kawagoe, Y., Greve, L.C., Kreuz, K., Delmer, D.P.: The experimental herbicide CGA $325^{\prime} 615$ inhibits synthesis of crystalline cellulose and causes accumulation of non-crystalline $\beta$-1,4-glucan associated with CesA protein. - Plant Physiol. 126: 981-992, 2001.

Peng, L., Zhang, L., Cheng, X., Fan, L.S., Hao, H.Q.: Disruption of cellulose synthesis by 2,6-dichlorobenzonitrile affects the structure of the cytoskeleton and cell wall construction in Arabidopsis. - Plant Biol. 15: 405-414, 2013.

Persson, S., Paredez, A., Carroll, A., Palsdottir, H., Doblin, M., Poindexter, P., Khitrov, N., Auer, M., Somerville, CR.: Genetic evidence for three unique components in primary cell-wall cellulose synthase complexes in Arabidopsis. - Proc. natl. Acad. Sci. USA 104: 15566-15571, 2007.

Persson, S., Wei, H., Milne, J., Page, G.P., Somerville, C.R.: Identification of genes required for cellulose synthesis by regression analysis of public microarray data sets. - Proc. nat. Acad. Sci. USA 102: 8633-8638, 2005.

Polko, J.K., Kieber, J.J.: The regulation of cellulose biosynthesis in plants. - Plant Cell 31: 282-296, 2019.

Ranik, M., Myburg. A.A.: Six new cellulose synthase genes from Eucalyptus are associated with primary and secondary cell wall biosynthesis. - Tree Physiol. 26: 545-556, 2006.

Richmond, T.A., Somerville, C.R.: The cellulose synthase superfamily. - Plant Physiol. 124: 495-498, 2000. 
Robert, S., Bichet, A., Grandjean, O., Kierzkowski, K., SatiatJeunemaître, B., Pelletier, S., Hauser, M.T., Höfte, H., Vernhettes, S.: An Arabidopsis endo-1,4- $\beta$-D-glucanase involved in cellulose synthesis undergoes regulated intracellular cycling. - Plant Cell 17: 3378-3389, 2005.

Roberts, A.W., Bushoven, J.T.: The cellulose synthase (CESA) gene superfamily of the moss Physcomitrella patens. - Plant mol. Biol. 63: 207-219, 2007.

Roberts, A.W., Roberts, E.M.: Evolution of the cellulose synthase (CesA) gene family: insights from green algae and seedless plants. In: Brown, R.M., Saxena, I.M. (ed.): Cellulose:Mmolecular and Structural Biology. Pp. 17-34. Springer, Dordrecht 2007

Roberts, E.M., Roberts, A.W.: A cellulose synthase (CESA) gene from the red alga Porphyra yezoensis (Rhodophyta). - J. Phycol. 45: 203-212, 2009.

Ross, P., Mayer, R., Benziman, M.: Cellulose biosynthesis and function in bacteria. - Microbiol. Rev. 55: 35-58, 1991.

Roudier, F., Fernandez, A.G., Fujita, M., Himmelspach, R., Borner, G.H., Schindelman, G., Song, S., Baskin, T.I., Dupree, P., Wasteneys, G.O., Benfey, P.N.: COBRA, an Arabidopsis extracellular glycosyl-phosphatidyl inositol-anchored protein, specifically controls highly anisotropic expansion through its involvement in cellulose microfibril orientation. - Plant Cell 17: 1749-1763, 2005.

Sánchez-Rodríguez, C., Bauer, S., Hématy, K., Saxe, F., Ibáñez, A.B., Vodermaier, V., Konlechner, C., Sampathkumar, A., Rüggeberg, M., Aichinger, E., Neumetzler, L., Burgert, I., Somerville, C., Hauser, M.T., Persson, S.: CHITINASELIKE1/POM-POM1 and its homolog CTL2 are glucaninteracting proteins important for cellulose biosynthesis in Arabidopsis. - Plant Cell 24: 589-607, 2012.

Satiat-Jeunemaitre, B.: Spatial and temporal regulations in helicoidal extracellular matrices: comparison between plant and animal systems. - Tissue Cell 24: 315-334, 1992.

Saxena, I.M., Brown, R.M., Jr.: Identification of cellulose synthase(s) in higher plants: sequence analysis of processive $\beta$-glycosyltransferases with the common motif ' $D, D$, D35Q(R,Q)XRW‘. - Cellulose 4: 33-49, 1997.

Saxena, I.M., Lin, F.C., Brown, R.M. Jr.: Cloning and sequencing of the cellulose synthase catalytic subunit gene of Acetobacter xylinum. - Plant mol. Biol. 15: 673-683, 1990.

Scheible, W.R., Eshed, R., Richmond, T., Delmer, D., Somerville, C.: Modifications of cellulose synthase confer resistance to isoxaben and thiazolidinone herbicides in Arabidopsis $\mathrm{Ixr} 1$ mutants. - Proc. nat. Acad. Sci. USA 98: 10079-10084, 2001.

Schindelman, G., Morikami, A., Jung, J., Baskin, T.I., Carpita, N.C., Derbyshire, P., McCann, M.C., Benfey, P.N.: COBRA encodes a putative GPI-anchored protein, which is polarly localized and necessary for oriented cell expansion in Arabidopsis. - Genes Dev. 15: 1115-1127, 2001

Sethaphong, L., Davis, J.K., Slabaugh, E., Singh, A., Haigler, C.H.: Prediction of the structures of the plant-specific regions of vascular plant cellulose synthases and correlated functional analysis. - Cellulose 23: 145-161, 2016.

Sethaphong, L., Haigler, C.H., Kubicki, J.D., Zimmer, J., Bonetta, D., De Bolt, S., Yingling, Y.G.: Tertiary model of a plant cellulose synthase. - Proc. nat. Acad. Sci. USA 110: 7512-7517, 2013.

Shaw, S.L., Kamyar, R., Ehrhardt, D.W.: Sustained microtubule treadmilling in Arabidopsis cortical arrays. - Science 300: 1715-1718, 2003.

Slabaugh, E., Davis, J.K., Haigler, C.H., Yingling, Y.G., Zimmer, J.: Cellulose synthases: new insights from crystallography and modeling. - Trends Plant Sci. 19: 99-106, 2014.

Speicher, T.L., Li, P.Z., Wallace, I.S.: Phosphoregulation of the plant cellulose synthase complex and cellulose synthase-like proteins. - Plants (Basel) 7: 52, 2018.

Sullivan, S., Ralet, M.C., Berger, A., Diatloff, E., Bischoff, V., Gonneau, M., Marion-Poll, A., North, H.M.: CESA5 is required for the synthesis of cellulose with a role in structuring the adherent mucilage of Arabidopsis seeds. - Plant Physiol. 156: 1725-1739, 2011

Szyjanowicz, P.M., McKinnon, I., Taylor, N.G., Gardiner, J., Jarvis, M.C., Turner, S.R.: The irregular xylem 2 mutant is an allele of korrigan that affects the secondary cell wall of Arabidopsis thaliana. - Plant J. 37: 730-740, 2004.

Tanaka, K., Murata, K., Yamazaki, M., Onosato, K., Miyao, A., Hirochika, H.: Three distinct rice cellulose synthase catalytic subunit genes required for cellulose synthesis in the secondary wall. - Plant Physiol. 133: 73-83, 2003.

Taylor, N.G.: Identification of cellulose synthase AtCesA7 (IRX3) in vivo phosphorylation sites - a potential role in regulating protein degradation. - Plant mol. Biol. 64: 161-171, 2007.

Taylor, N.G., Howells, R.M., Huttly, A.K., Vickers, K., Turner, S.R.: Interactions among three distinct CesA proteins essential for cellulose synthesis. - Proc. nat. Acad. Sci. USA 100: 14501455,2003

Thomas, L.H., Forsyth, V.T., Sturcová, A., Kennedy, C.J., May, R.P., Altaner, C.M., Apperley, D.C., Wess, T.J., Jarvis, M.C.: Structure of cellulose microfibrils in primary cell walls from collenchyma. - Plant Physiol. 161: 465-476, 2013.

Timmers, J., Vernhettes, S., Desprez, T., Vincken, J.P., Visser, R.G., Trindade, L.M.: Interactions between membrane-bound cellulose synthases involved in the synthesis of the secondary cell wall. - FEBS Lett. 583: 978-982, 2009.

Tsekos, I.: The sites of cellulose synthesis in algae: diversity and evolution of cellulose-synthesizing enzyme complexes. - J. Phycol. 35: 635-655, 1999.

Turner, S.R., Somerville, C.R.: Collapsed xylem phenotype of Arabidopsis identifies mutants deficient in cellulose deposition in the secondary cell wall. - Plant Cell 9: 689-701, 1997.

Vain, T., Crowell, E.F., Timpano, H., Biot, E., Desprez, T., Mansoori, N., Trindade, L.M., Pagant, S., Robert, S., Höfte, H., Gonneau, M., Vernhettes, S.: The cellulase KORRIGAN is part of the cellulose synthase complex. - Plant Physiol. 165: 1521-1532, 2014.

Vandavasi, V.G., Putnam, D.K., Zhang, Q., Petridis, L., Heller, W.T., Nixon, B.T., Haigler, C.H., Kalluri, U., Coates, L., Langan, P., Smith, J.C., Meiler, J., O'Neill, H.: A structural study of CESA1 catalytic domain of Arabidopsis cellulose synthesis complex: evidence for CESA trimers. - Plant Physiol. 170: 123-135, 2016.

Vanholme, B., Desmet, T., Ronsse, F., Rabaey, K., Van Breusegem, F., De Mey, M., Soetaert, W., Boerjan, W.: Towards a carbonnegative sustainable bio-based economy. - Front. Plant Sci. 4: 174, 2013.

Vergara, C.E., Carpita, N.C.: $\beta$-D-glycan synthases and the CesA gene family: lessons to be learned from the mixed-linkage $(1 \rightarrow 3),(1 \rightarrow 4) \beta$-D-glucan synthase. - Plant mol. Biol. 47: 145$160,2001$.

Viëtor, R.J., Newman, R.H., Ha, M.A., Apperley, D.C., Jarvis, M.C.: Conformational features of crystal-surface cellulose from higher plants. - Plant J. 30: 721-731, 2002.

Wang, J., Elliott, J.E., Williamson, R.E.: Features of the primary wall CESA complex in wild type and cellulose-deficient mutants of Arabidopsis thaliana. - J. exp. Bot. 59: 2627-2637, 2008.

Wang, J., Howles, P.A., Cork, A.H., Birch, R.J., Williamson, R.E.: Chimeric proteins suggest that the catalytic and/or C-terminal 
domains give CesA1 and CesA 3 access to their specific sites in the cellulose synthase of primary walls. - Plant Physiol. 142: 685-695, 2006.

Wang, C., Li, J., Yuan, M.: Salt tolerance requires cortical microtubule reorganization in Arabidopsis. - Plant Cell Physiol. 48: 1534-1547, 2007.

Wang, T., McFarlane, H.E., Persson, S.: The impact of abiotic factors on cellulose synthesis. - J. exp. Bot. 67: 543-552, 2016.

Watanabe, Y., Meents, M.J., McDonnell, L.M., Barkwill, S., Sampathkumar, A., Cartwright, H.N., Demura, T., Ehrhardt, D.W., Samuels, A.L., Mansfield, S.D.: Visualization of cellulose synthases in Arabidopsis secondary cell walls. Science 350: 198-203, 2015.

Wightman, R., Turner, S.: Trafficking of the plant cellulose synthase complex. - Plant Physiol. 153: 427-432, 2010.

Wong, H.C., Fear, A.L., Calhoon, R.D., Eichinger, G.H., Mayer, R., Amikam, D., Benziman, M., Gelfand, D.H., Meade, J.H., Emerick, A.W., Bruner, R., Ben-Bassat, A., Tal, R.: Genetic organization of the cellulose synthase operon in Acetobacter xylinum. - Proc. nat. Acad. Sci. USA 87: 8130-8134, 1990.

Xie, L., Yang, C., Wang, X.: Brassinosteroids can regulate cellulose biosynthesis by controlling the expression of CESA genes in Arabidopsis. - J. exp. Bot. 62: 4495-4506, 2011.

Zhang, T., Mahgsoudy-Louyeh, S., Tittmann, B., Cosgrove, D.J.: Visualization of the nanoscale pattern of recently-deposited cellulose microfibrils and matrix materials in never-dried primary walls of the onion epidermis. - Cellulose 21: 853862,2014

Zhang, Y., Nikolovski, N., Sorieul, M., Vellosillo, T., McFarlane, H.E., Dupree, R., Kesten, C., Schneider, R., Driemeier, C., Lathe, R., Lampugnani, E., Yu, X., Ivakov, A., Doblin, M.S., Mortimer, J.C., Brown, S.P., Persson, S., Dupree, P.: Golgi-localized STELLO proteins regulate the assembly and trafficking of cellulose synthase complexes in Arabidopsis. Nat. Commun. 7: 11656, 2016.

Zhong, R., Lee, C., Ye, Z.H.: Evolutionary conservation of the transcriptional network regulating secondary cell wall biosynthesis. - Trends Plant Sci. 15: 625-632, 2010.

Zhong, R., Ye, Z.H.: MYB46 and MYB83 bind to the SMRE sites and directly activate a suite of transcription factors and secondary wall biosynthetic genes. - Plant Cell Physiol. 53: 368-380, 2012.

Zhu, X., Li, S., Pan, S., Xin, X., Gu, Y.: CSI1, PATROL1, and exocyst complex cooperate in delivery of cellulose synthase complexes to the plasma membrane. - Proc. nat. Acad. Sci. USA 115: E3578-E3587, 2018.

Zuo, J., Niu, Q.W., Nishizawa, N., Wu, Y., Kost, B., Chua, N.H.: KORRIGAN, an Arabidopsis endo-1,4-beta-glucanase, localizes to the cell plate by polarized targeting and is essential for cytokinesis. - Plant Cell 12: 1137-1152, 2000. 